DOI: $10.17805 /$ zpu.2016.1.23

\title{
«Влюбленный Гамлет» как тема поэзии XX века
}

\author{
М. П. КИЗИМА \\ (МОСКОВСКИЙ ГОСУДАРСТВЕННЫЙ ИНСТИТУТ МЕЖДУНАРОДНЫХ ОТНОШЕНИЙ \\ (УНИВЕРСИТЕТ) МИД РОССИИ)
}

В творчестве У. Шекспира любовная тема играет значительную роль. По мнению автора, тот факт, что герой способен или не способен любить, зачастую определяет смысловую палитру его характера даже тогда, когда сама тема любви, казалось бы, не является центральной. В шекспировском «Гамлете» доминирующей является сюжетная линия «Гамлет и Датское королевство», которой подчинена линия «Гамлет и Офелия». Однако драматург выстраивает сюжет таким образом, чтобы показать теснейшую взаимосвязь этих линий и представить трагические изъяны героя - зацикленность на собственном «я», расщепленность сознания. Принц Датский предпринимает попытки собрать свои волю, разум, чувства, воображение воедино, чтобы обрести целостность сознания и вытекающую из нее способность к действию. Но все его усилия в итоге заканчиваются внутренним поражением, цена которого - безумие и гибель Офелии - особенно горька для «сердца благородного» (акт V, сцена 2).

Мотив любовной несостоятельности Гамлета стал особенно актуальным в поэзии ХХ столетия, когда на закате Нового времени возникло ощущение кризиса западной цивилизации. Так, Т. С. Элиот, видевший в расщепленности сознания одну из бед современного человека, знак его внутреннего упадка, представил героя своей иронической поэмы «Любовная песнь Дж. Альфреда Пруфрока» (1915) как современную вариацию на тему «влюбленного Гамлета», а его «любовную песнь» - как откровенное признание в недееспособности. М. И. Цветаева в стихотворении «Диалог Гамлета с совестью» (1923) также упрекнула шекспировского героя в неспособности любить.

Рассмотрев примеры из творчества Элиота и Цветаевой, автор приходит к выводу, что шекспировский Гамлет воплотил в себе многие достоинства и недостатки человека Нового времени. Проследив трансформацию этого типа человеческой личности, поэты обратили пристальное внимание на ее внутренние проблемы, которые приводят ее в ХХ в. к экзистенциальной катастрофе: человек утрачивает не только свой героический потенциал, но и такое основополагающее качество, как способность любить. Тема «влюбленного Гамлета» дала поэтам XX в. возможность глубже осознать и выразить трагизм мировидения современного человека.

Ключевые слова: У. Шекспир; Т. С. Элиот; М.И.Цветаева; образ Гамлета, «влюбленный Гамлет»; поэзия XX в.; влияние Шекспира

$\mathbf{R}$ творчестве Шекспира тема любви играет особую роль: способность или неспособ-

$\mathrm{B}$ ность героя к любви нередко определяет смысловую палитру его образа даже в тех случаях, когда сама любовная тема, казалось бы, не является главной. Так, в «Гамлете» сюжетная линия «Гамлет и Офелия» подчинена доминирующей линии «Гамлет и Аатское королевство». Между тем самим развитием сюжета Шекспир выявляет теснейшую взаимосвязь этих линий и раскрывает трагические изъяны героя погруженность в собственное «я», расщепленность сознания. Гамлет пытается собрать воедино волю, разум, чувства, воображение - ведь способность человека к действию основывается на такой целостности сознания, но сделать это ему удается лишь частично. Безумие и смерть Офелии - трагическая цена его внутреннего поражения, особенно горькая для «сердца благородного», - именно благородство сердца Гамлета подчеркивает Горацио в заключительной сцене трагедии, когда принц Аатский гибнет: "Now cracks a noble heart" (V, 2) (Shakespeare, 1983: 907).

В поэзии XX в. эта сторона образа Гамлета - несостоятельность в любви - стала своеобразным мерилом в постижении кризиса западной культуры и ее благородного 
героя на закате Нового времени; тема «влюбленного Гамлета» была важным мотивом и в англоязычной, и в русской поэзии.

\section{АЖ. ААЬФРЕА ПРУФРОК КАК ВАРИАЦИЯ НА ТЕМУ ГАМАЕТА}

Томас Стернз Элиот (1888-1965), один из основоположников модернизма, представил героя своего иронического стихотворения «Аюбовная песнь Аж. Альфреда Пруфрока» (The Love Song of J. Alfred Prufrock, 1915) как современную вариацию на тему Гамлета.

Американец по происхождению, переехавший в лийское подданство, Т. С. Элиот был жестким критиком современной цивилизации, в «расщепленности сознания» (“dissociation of sensibility") он видел одну из бед эпохи, знак распада. Элиот глубоко сомневался в самой идее прогресса; Первая мировая война усилила эти его настроения, и современный мир предстал в его поэзии «бесплодной землей».

Стремясь осмыслить ход истории, Элиот обращался к ее важнейшим культурным вехам: своеобразный диалог с культурой Возрождения, положившей начало Новому времени, стал одной из доминант в его творчестве; «Аюбовная песнь Аж. Альфреда Пруфрока» - пример такого творческого взаимодействия.

Стихотворению предшествует эпиграф из Аанте («Ад», XXVII, 61-66): «Если бы я полагал, что отвечаю тому, кто может возвратиться в мир, это пламя не дрожало бы; но, если правда, что никто никогда не возвращался живым из этих глубин, я отвечу тебе, не опасаясь позора» (цит. по: Элиот, 2000: 11). Само стихотворение начинается затем как непосредственный отклик на эти слова, продолжение разговора: "Let us go then, you and I" (The new Oxford book ..., 1975: 873). Все это задает художественному пространству с самого начала особое духовное измерение: поэт рисует картину современного уродливо-призрачного города, эпиграф же недвусмысленно указывает на то, что современный мир - вместилище душ погибших, Ад, из которого нет выхода.

Перекличка первой строфы с эпиграфом особенно существенна потому, что стихотворение написано в форме драматического монолога. Оно полно не только внутреннего драматизма, но сохраняет и внешние приметы драматического действия, готовящие нас к монологу Пруфрока - современного Гамлета.

Пруфрок лишен высоких помыслов и целей своего «предка», серьезности и значительности его внутренних переживаний. Гамлет мучительно размышлял над вопросами чести, правды, справедливости и в этом контексте - оправданности действия; Пруфрок же опасается, «как бы чего не вышло», если он все же решится на любовное признание: его пространный монолог с претензиями на философствование и рефлексию фактически ничтожен и банален, он весь - свидетельство бессилия и паралича воли. В «любовной песне» Пруфрока нет ни пылких излияний чувств, ни восхищения объектом любви; все переживания героя сосредоточены на его собственной персоне, а основное его чувство - страх действия.

\section{«БОАЬНОЕ ВРЕМЯ» И ИРОНИЯ}

Элиот показывает, что в XX в., когда эпоха Нового времени клонится к закату, произошло вырождение духовных способностей человека: то, что было вначале симптомом, привело в итоге к неизлечимой болезни. Поэт создает образ больного мира и в построении этого образа использует важные образные линии трагедии Шекспира - он словно протягивает их в XX в. 
Гамлет восклицал, что тело мира искалечено, полагал, что он рожден исправить этот «вывихнутый» мир (заметим, что в оригинале речь идет о времени, о мире как эпохе):

The time is out of joint; O cursed spite,

That ever I was born to set it right!

(I, 5) (Shakespeare, 1983: 878)

В переводе М. Аозинского эти строки звучат так:

Век расшатался - и скверней всего,

Что я рожден восстановить его!

(Шекспир, 1977: 171)

Образ больного времени открывает и монолог Пруфрока, но век уже не просто расшатался, он - пациент под наркозом на операционном столе: “...the evening is spread out against the sky / Like a patient etherised upon a table" (The new Oxford book ..., 1975: 873).

Во всех деталях своего стихотворения Элиот рисует картину действительности $\mathrm{XX}$ в., современного города, его быта, и в этой картине превалируют образы бессилия, тягостного застоя. Обездвиженность, однако, соседствует с бессмысленной - но претендующей на глубокий смысл - суетой. Монолог героя сопровождает характерный ироничный рефрен, показывающий, как высокие смыслы Возрождения стали для общества XX в. мишурой, внешним украшением, пустым ритуалом, скрывающим за видимой многозначительностью внутреннюю ничтожность и механистичность:

In the room the women come and go

Talking of Michelangelo.

(там же)

Ирония пронизывает каждую строку этого произведения. Выспренние размышления Пруфрока о времени и о себе, его попытка приблизиться к гамлетовскому главному вопросу (“To lead you to an overwhelming question...") заканчиваются в итоге решением все вопросы просто отложить до чая - ведь время еще будет:

Time for you and time for me,

And time yet for a hundred indecisions,

And for a hundred visions and revisions,

Before the taking of a toast and tea.

(там же)

Шекспир не исключал смысловой иронии в отношении своего трагического героя, он указывал на внутреннюю иронию его великих планов. Так, Гамлет полагает, что он рожден исправить «вывихнутый» мир, но сам он при этом далек от совершенства и с трудом несет свое собственное тело - он тучен и страдает одышкой; в сцене дуэли королева говорит об этом: “He's fat and scant of breath" (V, 2) (Shakespeare, 1983: 906).

Элиот, в свою очередь, подчеркивает физическую немощь Пруфрока. Пруфрок сетует на то, что стареет, что у него тощие ноги, голова его плешива, он сидит на диете и не решается съесть даже персик. Основной вопрос его саморефлексии - это: "Аа как же я себе позволю? Аа как же я начну?»:

And indeed there will be time

To wonder, 'Do I dare?' and, 'Do I dare?'

Time to turn back and descend the stair,

With a bald spot in the middle of my hair...

(The new Oxford book ..., 1975: 874)

Но для Пруфрока этот жалкий вопрос тождествен вмешательству во вселенную: 
Do I dare

Disturb the universe?

(там же)

Несмотря на все внутренние приготовления - постом, и плачем, и молитвой, Пруфрок так ни на что и не решается, - он испугался: “And in short, I was afraid” (там же: 875). «Аюбовная песнь» Пруфрока - томительные рассуждения, так и не приводящие его к признанию в любви.

Однако Пруфрок - не пародия на Гамлета, и общий тон стихотворения отнюдь не комичен: Элиот рисует трагическую картину убывания в мире не только героического начала, но и всех личностных качеств, страх современного человека перед жизнью как таковой, его недееспособность, проявляющуюся в том, что есть самое основополагающее - любовь. Образ Гамлета как благородного молодого человека Нового времени, созданный гением Шекспира, остается при этом мерилом достоинства. Пруфрок как молодой человек XX в. стремится примерить на себя этот образ, но его собственная внутренняя жизнь лишена достоинства, не может соответствовать серьезности и глубине гамлетовской мысли, он наследует лишь изъяны Гамлета, доводя их до логического предела - полного паралича воли. Пруфрок и сам после долгих потуг приблизиться к своему прообразу, вынужден признать, что он, увы, не Гамлет, а дотягивает разве что до кого-нибудь из услужливых членов свиты:

No! I am not Prince Hamlet, nor was meant to be;

Am an attendant lord...

(там же: 876)

В финале стихотворения Пруфрок дает оценку самому себе и себе подобным, в его монологе появляется обобщающее «мы». Последние строки рисуют картину обреченности таких людей - далекие от действительности и от человечности, живущие словно под толщей вод среди русалок, неспособные к человеческому контакту, они тонут, пробужденные человеческими голосами:

We have lingered in the chambers of the sea

By sea-girls wreathed with seaweed red and brown

Till human voices wake us, and we drown.

(там же)

\section{ГАМАЕТ И РЫЦАРСТВО В ПОЭЗИИ М. ЦВЕТАЕВОЙ}

Неспособность любить - главный упрек, который бросает Гамлету и Марина Цветаева (1892-1941). Младшая современница Элиота, столь же остро, как и он, чувствовавшая кризисное состояние общества и личности, Цветаева была поэтом иного душевного склада, иных творческих воззрений: ее поэзия по своему звучанию близка к неоромантизму. Неоромантическая эстетика оказала существенное воздействие на развитие европейской литературы ХХ в. - и поэзии, и прозы, и драматургии, - поскольку не только затрагивала самый нерв эпохи, но противопоставляла миру тотального отчуждения личности и оскудения человеческого духа романтический идеал гармонии и преодоления, возможности торжества личности, несмотря на господствующую пошлость и буржуазную обыденность.

Современному сознанию - безвольному и исполненному страха перед жизнью Цветаева противополагала образы внутреннего благородства, рыцарственности, неподвластной времени, сохранившей в веках «благородное сердце». О том, насколько глубоким и искренним был этот романтический порыв Цветаевой, свидетельствует 
тот факт, что данная образная линия пронизывает ее самые личные - любовные стихи, рассказывающие о ее личном человеческом опыте, через эти образы она осмысляет свою собственную жизнь. В свойственном поэтам-романтикам духе она соединяет свою жизнь и творчество, но «личные» стихотворения Цветаевой всегда направлены на постижение бытия, мира и человека, эпохи и Вечности - через призму рыцарского идеала. Так, в стихотворении «С. Э.», посвященном Сергею Эфрону, помеченном точной датой - «3 июня 1914, Коктебель», - она пишет:

Я с вызовом ношу его кольцо!

- Аа, в Вечности - жена, не на бумаге. -

Его чрезмерно узкое лицо

Подобно шпаге.

(Цветаева, 1990: 28)

А завершает данное стихотворение развернутый гимн рыцарству:

В его лице я рыцарству верна,

- Всем вам, кто жил и умирал без страху! -

Такие - в роковые времена -

Слагают стансы - и идут на плаху.

(там же: 29)

Как видим, несмотря на разность художественных темпераментов и эстетических подходов, и для Элиота, и для Цветаевой «жить и умирать без страху» - качество, которым не обладает современный человек, оно присуще рыцарям, а не буржуа. В стихотворении Цветаевой это качество объединяет во все века поэтов и героев; в мире стихотворения Элиота оно утрачено полностью.

\section{АИРИЧЕСКИЙ АИААОГ ГАМАЕТА С СОВЕСТЬЮ}

Не менее личными обстоятельствами (непростыми отношениями с Б. Пастернаком) были навеяны и раздумья Цветаевой над образом Гамлета «Аиалог Гамлета с совестью» (5 июня 1923 г.), но стихотворение выходит по своему значению далеко за пределы частной жизни, в нем - осмысление роковых изъянов «благородного сердца» принца Аатского и его современных потомков.

Существенным представляется тот факт, что Цветаева выбирает форму лирического диалога - весьма значимую и для английской поэтической традиции. Надо сказать, что диалогичность в целом присуща творчеству Цветаевой и данное стихотворение весьма органично входит в ее поэтическое наследие и по своей форме, и по содержанию. Избранная форма позволяет Цветаевой раскрыть сознание героя изнутри (ведь перед нами диалог человека с совестью - его внутренним голосом), соответствует образу героя (саморефлексия - характернейшая черта Гамлета), к тому же она драматургична: текст стихотворения звучит как сцена трагедии - и тем самым Марина Цветаева как бы вступает в непосредственный творческий диалог с Шекспиром.

\footnotetext{
- На дне она, где ил

И водоросли... Спать в них

Ушла, - но сна и там нет!

- Но я ее любил,

Как сорок тысяч братьев

Аюбить не могут!
}

- Гамлет!

На дне она, где ил:

Ил!.. И последний венчик

Всплыл на приречных бревнах.. 
- Но я ее любил,

Как сорок тысяч...

Все ж, чем один любовник.

- Меньше,

На дне она, где ил.

- Но я ее -

$$
\begin{array}{r}
\text { (недоуменно) } \\
\text { любил?? }
\end{array}
$$

(там же: 110-111).

Совесть как абсолютное нравственное начало, рассказывая о фактах, словно призывает Гамлета выйти из сосредоточенности на самом себе, взглянуть на действительность, на судьбу другого человека - невинно погибшей Офелии, чья загубленная душа не знает покоя. Но Гамлет всецело погружен в свое собственное «я», не способен выйти за его пределы. Голос совести вначале просто объективно описывает страшную картину смерти Офелии, на этом фоне любовное признание Гамлета звучит как несостоятельное самооправдание человека, глухого к голосу совести, и совесть вынуждена окликать, повторять, подчеркивать детали. Но все напрасно: Гамлет не способен критически оценить содеянное, он все так же и в тех же словах утверждает силу своей любви, так что совести приходится прервать его излияния и дать объективную оценку силе его чувства - сказать Гамлету прямо о его несостоятельности: «Меньше, / Все ж, чем один любовник». Аишь эта объективная оценка заставляет Гамлета усомниться в силе своей любви: в итоге он уже не утверждает, а сомневается, его последняя реплика завершается двойным знаком вопроса, обращенным и к самому себе и к читателям. Гамлет так и остается в нерешительности, он не в силах не только действовать, но и понять, что же происходит в его сердце, а может быть, оно, всецело занятое самим собою, и вовсе не способно на любовь. Меж тем данная нерешительность оплачена ценой человеческой жизни, и под двойным знаком вопроса стоит «благородство» холодного сердца.

\section{ЗАКАЮЧЕНИЕ}

Итак, как мы могли видеть, тема «влюбленного Гамлета» занимает важное место в поэзии ХХ в., она является своего рода образной парадигмой для осмысления кризиса европейской культуры XX в. Шекспировский Гамлет как прообраз человека Нового времени, в котором сложно переплелись и сила, и слабости, позволил поэтам проследить трансформацию этого типа человеческой личности, внутренние изъяны которой приводят ее в XX в. к глубочайшей катастрофе - утрате не только героического потенциала, но и такого основополагающего человеческого качества, как способность любить. Тема «влюбленного Гамлета» помогала поэтам XX в. понять трагические противоречия современного сознания.

\section{СПИСОК АИТЕРАТУРЫ}

Шекспир, У. (1977) Трагедии. Сонеты / послесл. Ю. Шведова. М. : Московский рабочий. $544 \mathrm{c.}$

Цветаева, М. И. (1990) Стихотворения. Поэмы. Араматические произведения / сост., подгот. текста, предисл. Е. Евтушенко. М. : Художественная литература. 398 с.

Элиот, Т. С. (2000) Полые люди / сост., предисл. и примеч. В. А. Топорова; пер. с англ. Н. Н. Берберовой и др. СПб. : ООО «Издательский дом “Кристалл”». 464 с. 
The new Oxford book of English verse, 1250-1950 (1975) / chosen and ed. by H. Gardner. Oxford : Clarendon Press. 974 p.

Shakespeare, W. (1983) The complete works / ed., with a glossary by W. J. Craig, M. A. L. : Henry Pordes. 1264 p.

Аата поступления: 12.01.2016 г.

\section{'HAMLET IN LOVE' AS A THEME IN 20TH CENTURY POETRY \\ M. P. KIZIMA \\ (MOSCOW STATE INSTITUTE OF INTERNATIONAL RELATIONS (UNIVERSITY) OF THE MINISTRY OF FOREIGN AFFAIRS OF RUSSIA)}

Love plays a special role in the works of Shakespeare: capacity or in-capacity to love often determines the whole spectrum of meaning of a hero's image, - even in cases when love is not apparently the main theme. Thus, in Hamlet the plotline of 'Hamlet and Ophelia' is subordinated to the dominant line of 'Hamlet and the Kingdom of Denmark'; yet, through the development of the plot Shakespeare shows how closely interconnected these lines are, how they both throw light on the tragic faults of the hero: the absorption with his own self, the dissociation of his sensibility. Hamlet strives to collect his will, his reason, feelings, and imagination; for man's capacity to act depends on the wholeness of his sensibility. However, his success is only partial: Ophelia's madness and death are a tragic price of Hamlet's inner defeat, - all the more poignant for "a noble heart" (Act V, Scene 2).

In the 20th century poetry Hamlet's failure in love was subsumed by the comprehension of the crisis of Western culture and its noble hero in the late modern times; the theme of 'Hamlet in love' became an important motif in English, as well as in Russian poetry. T. S. Eliot stressed that dissociation of sensibility was one of the key predicaments of modern man, a sign of his inner decline; in "The Love Song of J. Alfred Prufrock" (1915) T. S. Eliot made the speaker of his poem a modern ironic variation on Hamlet, and his 'love song' - a declaration of human inefficacy. The incapacity to love was the main fault Marina Tsvetaeva found with Hamlet ("Hamlet's Dialogue with His Conscience", 1923).

An analysis of the poems by Eliot and Tsvetaeva allows us to conclude that Shakespeare's Hamlet as a prototypic modern man with his complex mix of strengths and weaknesses helped the poets trace the transformation of this type of personality. In the 20th century its internal flaws led to a catastrophe, a loss of both hero status and the capacity for love. The theme of 'Hamlet in love' made it possible for 20th century poets to grasp the tragic contradictions within the modern consciousness.

Keywords: W. Shakespeare; T. S. Eliot; Marina Tsvetaeva; character of Hamlet; 'Hamlet in love' theme; 20th century poetry; Shakespeare's influence

\section{REFERENCES}

Shakespeare, W. (1977) Tragedii. Sonety [Tragedies. Sonnets] / afterword by Yu. Shvedov. Moscow, Moskovskii rabochii Publ. 544 p. (In Russ.).

Tsvetaeva, M. I. (1990) Stikbotvoreniia. Poemy. Dramaticheskie proizvedeniia [Verses. Poems. Dramatic works]/ comp., ed. and foreword by E. Evtushenko. Moscow, Khudozhestvennaia literatura Publ. 398 p. (In Russ.).

Eliot, T. S. (2000) Polye liudi [The hollow men] / comp., foreword and notes by V. L. Toporov; transl. from English by N. N. Berberova et al. St. Petersburg, Kristall LLC Publ. 464 p. (In Russ.).

The new Oxford book of English verse, 1250-1950 (1975) / chosen and ed. by H. Gardner. Oxford, Clarendon Press. 974 p.

Shakespeare, W. (1983) The complete works / ed., with a glossary by W. J. Craig, M. A. London, Henry Pordes. 1264 p. 
Кизима Марина Прокофьевна - доктор филологических наук, профессор кафедры мировой литературы и культуры Московского государственного института международных отношений (Университета) Министерства иностранных дел Российской Федерации. Адрес: 119454, Россия, г. Москва, проспект Вернадского, д. 76. Тел.: +7 (495) 434-93-92. Эл. адрес: Кizimam@yandex.ru

Kizima Marina Prokofievna, Doctor of Philology, Professor, Department of World Literature and Culture, Moscow State Institute of International Relations (University) of the Ministry of Foreign Affairs of Russia (MGIMO-University). Postal address: 76 Vernadsky Avenue, 119454 Moscow, Russian Federation. Tel.: +7 (495) 434-93-92. E-mail: Kizimam@yandex.ru 